\title{
Do water regimes affect iron-plaque formation and microbial communities in the rhizosphere of paddy rice?
}

\author{
Xue-Ping Chen'1, Wei-Dong Kong1', Ji-Zheng He1, Wen-Ju Liu1, 2, Sally E. Smith³, F. Andrew Smith³, and \\ Yong-Guan Zhu1* \\ ${ }^{1}$ Research Center for Eco-environmental Sciences, Chinese Academy of Sciences, Beijing 100085, China \\ 2 College of Natural Resources and Environment, Hebei Agricultural University, Baoding 071001, China \\ 3 Soil and Land System, School of Earth and Environmental Sciences, The University of Adelaide, South Australia 5005, Australia
}

\begin{abstract}
Pot experiments were conducted to investigate the effect of soil water regimes on the formation of iron (Fe) plaque on the root surface of rice seedlings (Oryza sativa L.) and on the microbial functional diversity in a paddy soil. The rice seedlings were subjected to three moisture regimes (submergence, $100 \%$, and $60 \%$ water-holding capacity [WHC]), and were grown for 5 and 11 weeks. Aerobic lithotrophic Fe(II)-oxidizing (FeOB) and acetate-utilizing Fe(III)-reducing bacteria (FeRB) in the rhizosphere and non-rhizosphere soil were determined at 5 weeks using the most probable number (MPN) method. The carbon substrate use patterns of the microbial communities in the rhizosphere and non-rhizosphere soil samples were determined at 11 weeks using Biolog-GN2 plates. The amount of Fe plaque (per unit dry root weight) was much higher under submerged conditions than at lower soil moisture contents and decreased with plant age. There was a positive correlation between the amount of Fe plaque and phosphorus accumulated in the Fe plaque at both sampling times $(r=0.98$ and 0.92 , respectively, $n=12)$. Numbers of FeOB and FeRB in the submerged soil were lower than in aerobic soil, but by two orders of magnitude higher in the rhizosphere than in the bulk soil. On the other hand, the functional diversity of the rhizosphere microbial communities was much higher than that of the non-rhizosphere soil, irrespective of soil water regimes. We conclude that soil flooding results in a decreased number and diversity of Fe-oxidizing/reducing bacteria, while increasing the Fe-plaque formation.
\end{abstract}

Key words: Biolog / Fe(II)-oxidizing bacteria (FeOB) / Fe(III)-reducing bacteria (FeRB) / most probable number / Shannon Index

Accepted September 18, 2007

\section{Introduction}

Iron (Fe) plaque is a deposit of reddish-brown Fe oxides (hydroxides, oxyhydroxides) on the root surfaces of aquatic plants (Chen et al., 1980). Rice, a major aquatic crop plant, usually forms Fe plaque on its root surfaces. The oxides in Fe plaque are commonly dominated by poorly crystalline forms such as ferrihydrite, but can contain more crystalline Fe forms such as lepidocrocite $(\gamma-\mathrm{FeOOH})$ and/or goethite $(\alpha-\mathrm{FeOOH})$ (Chen et al., 1980; Hansel et al., 2001). The oxidized Fe compounds, whose chemical and physical properties are similar to those of Fe oxides in soil, have a high capacity for binding phosphorus (P) (Chistensen et al., 1997) and may influence the assimilation of $\mathrm{P}$ by aquatic plants. Formation of Fe plaque is mainly due to the oxidation of ferrous to ferric iron, which is facilitated by the release of oxygen and oxidants into the rhizosphere (Chen et al., 1980; Ando et al., 1983). The amounts of Fe plaque formed may depend on the availability of ferrous $\mathrm{Fe}$ in the vicinity of the root and the oxygenation capacity of the root system. The formation of Fe plaque on roots of wetland plants has been found to be related to soil chemical properties such as the amount of total free $\mathrm{Fe}(\mathrm{III})$ oxides and Fe carbonates (Macfie and Crowder, 1987), and close negative correlations have been found between redox potential and concentrations of Fe and manganese (Mn) plaques (Christensen and Wigand, 1998). Liu et al. (2004a) demonstrated that $P$ starvation might induce the formation of Fe plaque, and Fe plaque in turn may influence arsenate uptake by rice plants. In a recent study, Liang et al. (2006) confirmed that soil moisture regimes efficiently affected the Fe-plaque formation (6-fold higher under flooding condition than under field-capacity condition). In addition, it has been suggested that a rapid microbially mediated cycling of Fe occurs in the rhizosphere of Juncus roots under changing redox conditions (Küsel et al., 2003). The discovery of both lithotrophic Fe-oxidizing bacteria (FeOB) (Emerson et al., 1999) and Fe-reducing bacteria (FeRB) (King and Garey, 1999) on the roots of wetland plants indicates that plaque-associated microbes may directly influence plaque formation. Emerson et al. (1999) found that there was a positive correlation between cell numbers (FeOB) and the total amount of Fe present in Sagittaria australis, but the same correlation was not found for Leersia oryzoides. JohnsonGreen and Crowder (1991) also reported that axenic roots accumulated significantly more Fe oxides than did non-axenic roots. Moreover, Weiss et al. (2004) demonstrated that the percentage

* Correspondence: Yong-Guan Zhu; e-mail: ygzhu@ @rcees.ac.cn 
of poorly crystalline $\mathrm{Fe}(\mathrm{III})$ was significantly correlated with the percentage of Fe-reducing bacteria. Though the role of the microbial oxidation of $\mathrm{Fe}(\mathrm{II})$ in the formation of Fe plaque is still a matter of debate, the microorganisms must mediate the Fe biogeochemistry cycle both in the rhizosphere and the non-rhizosphere soil.

In addition to the formation of Fe plaque, we hypothesized that soil moisture contents also influence rhizosphere microbial communities and the microorganisms (FeOB and FeRB) which may be involved in rhizosphere Fe cycle. The goal of our study was (1) to examine how soil water content affect Fe-plaque formation on roots of rice; (2) to investigate the functional diversity of the microbial communities particularly the abundance of FeOB and FeRB in the rhizosphere and the bulk soil; and (3) to explore the interactions between FeOB and FeRB and Fe-plaque formation.

\section{Materials and methods}

\subsection{Preparation of rice seedlings}

Rice seeds (Oryza sativa L.) cv. Jiahua-1, which was previously identified to form abundant Fe plaque on its root, were sterilized in $30 \% \mathrm{H}_{2} \mathrm{O}_{2}$ (w:w) solution for $10 \mathrm{~min}$, followed by thorough-washing with de-ionized water. The seeds were germinated in non-sterilized moist perlite, washed with distilled water three times. After 3 weeks, uniform seedlings were transplanted into a rhizobag system, separating the rhizosphere from a bulk-soil compartment. The rhizobags were $37 \mu \mathrm{m}$ nylon meshbags, $6 \mathrm{~cm}$ in diameter, $7 \mathrm{~cm}$ in height, filled with $150 \mathrm{~g}$ soil, planted with one seedling, and transferred to PVC pots $(7.5 \mathrm{~cm}$ diameter, $14 \mathrm{~cm}$ height $)$. The gap between rhizo-bag and PVC pot was filled with $300 \mathrm{~g}$ of paddy soil from Jiaxing, Zhejiang province, China. The soil was a silty clay loam with $\mathrm{pH} 7.1\left(\mathrm{H}_{2} \mathrm{O}\right)$, a CEC of $7.45 \mathrm{cmol} \mathrm{kg}^{-1}, 14.6 \mathrm{~g} \mathrm{~kg}^{-1}$ organic $\mathrm{C}$, and $18.8 \mathrm{~g} \mathrm{~kg}^{-1} \mathrm{Fe}$. To ensure adequate mineral nutrition, $\mathrm{N}, \mathrm{P}$, and $\mathrm{K}$ were added at the start of the experiment at the following rates: $0.2 \mathrm{~g} \mathrm{~N} \mathrm{~kg}$ (urea), $0.03 \mathrm{~g} \mathrm{P} \mathrm{kg}\left(\mathrm{CaHPO}_{4} \cdot 2 \mathrm{H}_{2} \mathrm{O}\right), 0.08 \mathrm{~g} \mathrm{~K} \mathrm{~kg}\left(\mathrm{~K}_{2} \mathrm{SO}_{4}\right)$.

\subsection{Treatments}

The soil water-holding capacity (WHC) was measured according to the standard method recommended by the Soil Science Society of China $(L u, 1999)$. Plants were grown under three moisture regimes, maintained by weighing and irrigation with distilled water twice per day as follows: (1) submerged, maintaining a flood-water depth of 2-4 cm above the soil surface, (2) 100\% WHC, and (3) $60 \%$ WHC. Each treatment was replicated four times. After transplanted into the PVC tube, plants were grown for 5 and 11 weeks in a controlled-environment growth chamber with a $14 / 10 \mathrm{~h}$ light/dark cycle (260-350 $\mu \mathrm{mol}$ photons $\left.\mathrm{m}^{-2} \mathrm{~s}^{-1}\right)$, day/night temperature of $25^{\circ} \mathrm{C} / 20^{\circ} \mathrm{C}$, and $70 \%$ relative humidity.

\subsection{Soil sampling}

At harvest, nylon bags were carefully removed from the PVC pots. The soil adhering to the roots of individual plant was removed with an aseptic metal spoon and designated as rhizosphere soil (Nicolaisen et al., 2004). Non-rhizosphere soil was defined as soil without rice roots, i.e., outside of nylon bags. Fresh soil samples were kept at $4^{\circ} \mathrm{C}$ until substrate-utilization analyses and FeOB and FeRB enumeration.

\subsection{Extraction and determination of Fe plaque from roots}

Roots were washed with tap water to remove soil particles adhering to the root surface and rinsed using distilled water more than three times. The fresh root material was incubated for $60 \mathrm{~min}$ at $25^{\circ} \mathrm{C}$ in $40 \mathrm{~mL}$ of dithionite-citrate-bicarbonate (DCB solution) containing $0.03 \mathrm{M}$ sodium citrate $\left(\mathrm{Na}_{3} \mathrm{C}_{6} \mathrm{H}_{5} \mathrm{O}_{7}\right.$ - $2 \mathrm{H}_{2} \mathrm{O}$ ) and $0.125 \mathrm{M}$ sodium bicarbonate $\left(\mathrm{NaHCO}_{3}\right)$, with the addition of $0.6 \mathrm{~g}$ sodium dithionite $\left(\mathrm{Na}_{2} \mathrm{~S}_{2} \mathrm{O}_{4}\right)$. Roots were rinsed three times with deionized water, and the washing solution was added to the DCB extracts. The resulting solution was diluted to $100 \mathrm{~mL}$ with deionized water (Taylor and Crowder, 1983). After DCB extraction, roots and shoots were oven-dried at $70^{\circ} \mathrm{C}$ for $3 \mathrm{~d}$ and weighed. The concentrations of $\mathrm{Fe}$ and $\mathrm{P}$ in the DCB extracts were measured by an inductively coupled plasma-optical emission spectrometer (ICPOES, Optima 2000 DV, Perkin Elmer, USA).

\subsection{Substrate-use patterns}

The rhizosphere and bulk soil samples were collected to detect the physiological profiles of the community level (CLPP) by Biolog GN microplates (BIOLOG, Hayward, USA), containing 95 different carbon $(C)$ sources, according to the method firstly described by Garland and Mills (1991). Ten grams dry weight of fresh soil were mixed with $100 \mathrm{~mL}$ autoclaved $\mathrm{NaCl}(0.85 \%)$, agitated for $1 \mathrm{~min}$, and then put on ice for $1 \mathrm{~min}$, which was repeated three times. After further dilution in $0.85 \% \mathrm{NaCl}, 150 \mu \mathrm{L}$ bacterial suspension (1:1000 dilutions) was inoculated into each Biolog GN2 plate wells. This dilution was chosen because pre-tests had shown that it was the lowest dilution that did not cause interference in the assay by co-extracted soil components, causing unspecific turbidity and absorbance. The plates were cultured for up to $7 \mathrm{~d}$ at $25^{\circ} \mathrm{C}$ in the dark, and the color development was measured every $24 \mathrm{~h}$ at $590 \mathrm{~nm}$ using a microplate reader of Biolog Microstation System (Biolog Inc., Hayward, CA).

\subsection{Biolog-data analyses}

Final values for the GN2 plates were calculated as the optical-density readings at $590 \mathrm{~nm}$ minus the $\mathrm{A} 1$ (control) well optical density. Negative well optical-density values were set to zero. The average well-color development (AWCD) value was calculated as the mean of the 95 blanked optical-density values. Visual impression of GN2 plates indicated that bacterial growth occurred in a majority of the plates after $96 \mathrm{~h}$, so we chose the $96 \mathrm{~h}$-incubation period for evaluating bacterial plates. The Shannon index of diversity $(H)$ was used to determine the microbial richness (Schutter and Dick, 2001) and calculated as:

$$
H=-\left(\sum_{i=1}^{s} P_{i} \times \ln P_{i}\right),
$$


whith $P_{i}$ being the proportion of species $i$ in the sample, and

$P_{i}=A_{i} / \sum_{i=1}^{s} A_{i}$,

whith $A_{i}$ being the catabolic activity of $C$ source $i$ (negative $A_{i}$ values were set to zero). Shannon evenness, a measure of how evenly bacterial communities were distributed in soil samples, was calculated as $H^{\prime}=H /$ Ins, where $s$ is the number of $C$ sources with $A_{i}>0$. When significant $(\alpha=0.05)$ treatment differences were found, protected LSD values were calculated to separate the means. Shifts in physiological profiles of community level (CCLP) of different water regimes were analyzed by principal-component analysis (PCA) of normalized $96 \mathrm{~h}$ optical-density values. The utilization of substrate groups (carbohydrates, carboxylic acids, amino acids, amines and amides, polymers, and miscellaneous) within a plate were also analyzed (Zak et al., 1994).

\subsection{Enumeration of aerobic lithotrophic FeOB and acetate-utilizing FeRB}

An additional experiment was conducted under the same conditions as described above to investigate the abundance of aerobic lithotrophic FeOB and acetate-utilizing FeRB, using the most probable number (MPN) method (Weiss et al., 2003). The homogenized soil was diluted (1:100) and incubated for $1 \mathrm{~h}$ in a $10 \mathrm{mM}$ sodium pyrophosphate solution to detach the bacteria from the soil particles. The soil suspension was diluted to $10^{-3}$ to $10^{-8}$ in modified Wolfe's mineral media (MWMM) and incubated in gradient tubes for the enumeration of FeOB (Emerson et al., 1999). A three-tube MPN series was inoculated from each dilution tube, which was used as a source to inoculate Fe-reducing medium (Widdel and Bak, 1992), containing sulfate-free MWMM, $10 \mathrm{mM}$ sodium acetate, $50 \mathrm{mM}$ sodium bicarbonate, $0.01 \%$ yeast extract (w/v), $1 \mu \mathrm{L} \mathrm{mL}^{-1}$ Wolfe's trace minerals, and $10 \%$ poorly crystalline $\mathrm{Fe}(\mathrm{III})$ as $\mathrm{Fe}\left(\mathrm{NO}_{3}\right) \cdot 9 \mathrm{H}_{2} \mathrm{O}$, adjusted to $\mathrm{pH}$ 7-8 (Schwertmann and Cornell, 2000). The presence of FeOB was confirmed by the development of a discrete band at the oxic-anoxic interface within the gradient tube. The visual consumption of the $\mathrm{Fe}$ (III) oxides and the presence of $\mathrm{Fe}(\mathrm{II})$ was shown by color development with ferrozine (Sigma Chemical Co, adjusted to $\mathrm{pH} 7$ ), indicating the presence of FeRB (Stookey, 1970). A subset of tubes positive for FeOB and FeRB was examined microscopically to confirm cell growth. Abundance of FeOB and FeRB was calculated using the Most Probable Number Calculator version 4.05 (@)1996 Albert J. Klee, Risk Reducion Engineering Laboratory, United States Environmental Protection Agency, Cincinnati, Ohio, free software available at http://www.epa.gov/nerlcwww/ other.htm).

\subsection{Statistical analysis}

Principal-component analysis on the Biolog data, and analysis of variance (ANOVA) on plant biomass, Fe and $P$ concentrations, utilization of substrate groups, and Shannon diversity were performed using SPSS 11.5 . at $5 \%$-error probability.

\section{Results}

\subsection{Effect of water regimes on Fe-plaque formation and $P$ sequestration}

Rice roots in the submerged treatment developed reddishbrown coatings, the typical color of Fe oxides, while no visible Fe coatings were observed at $60 \% \mathrm{WHC}$ and $100 \% \mathrm{WHC}$. The amounts of Fe plaque differed significantly between soilmoisture treatments, ranging from 0.6 at $60 \% \mathrm{WHC}$ to $27.8 \mathrm{~g}$ $\mathrm{Fe} \mathrm{kg}^{-1}$ at soil submergence. Roots in the submerged treatment had the highest amounts of Fe plaque, and those in the other treatments had similar amounts of Fe plaque (Tab. 1). The amounts of Fe plaque harvested at 11 weeks were generally lower than those at 5 weeks.

The amount of $P$ adsorbed to the plaque increased significantly with the amount of plaque formed, and significant positive correlations were found (data not shown, Pearson coefficient $>0.9 ; p<0.05$ ).

\subsection{Biolog: Substrate-use patterns}

For the three different water regimes, the average well-color development (AWCD) generally followed a sigmoid pattern with incubation time (Fig. 1). The AWCD of plates inoculated with rhizosphere soil increased rapidly after $24 \mathrm{~h}$ and reached significantly higher values within $144 \mathrm{~h}$ than plates inoculated with bulk soil. For the rhizosphere soil, the AWCD values were not affected by soil moisture content. However, for the non-rhizosphere soil, AWCD values with $60 \%$ WHC were significantly higher than in the other two treatments.

The PCA clearly indicated the degree to which profiles for each community were unique and reproducible and was used to identify contribution rate of different carbon substrates in different soil samples. Principal-component analysis scores were obtained after analysis of the covariance matrix of $96 \mathrm{~h}$ OD590 values. The first covariance PC axis accounted for $34 \%$, the second accounted for $7 \%$ (Fig. 2). Principal-component axis 1 had the highest loadings on substrates for which there were consistent differences in the degree of substrate oxidation (i.e., OD590 values) between microorganism communities. Prinicipal-component analysis of Biolog GN meta-

Table 1: Iron and P concentrations in DCB extracts of rice seedling s with different soil moisture contents at 5 and 11 weeks.

\begin{tabular}{lllll}
\hline Water regime & \multicolumn{2}{l}{ Fe concentration $\left(\mathrm{g} \mathrm{kg}^{-1}\right)$} & \multicolumn{2}{l}{ P concentration $\left(\mathrm{g} \mathrm{kg}^{-1}\right)$} \\
\hline & 5 weeks & 11 weeks & 5 weeks & 11 weeks \\
Submerged & $27.8 \pm 0.8$ & $12.5 \pm 2.3$ & $0.73 \pm 0.08$ & $0.81 \pm 0.09$ \\
$100 \%$ WHC & $0.8 \pm 0.1$ & $0.6 \pm 0.1$ & $0.26 \pm 0.01$ & $0.18 \pm 0.03$ \\
$60 \%$ WHC & $2.3 \pm 0.5$ & $0.6 \pm 0.1$ & $0.32 \pm 0.03$ & $0.28 \pm 0.05$ \\
\hline
\end{tabular}




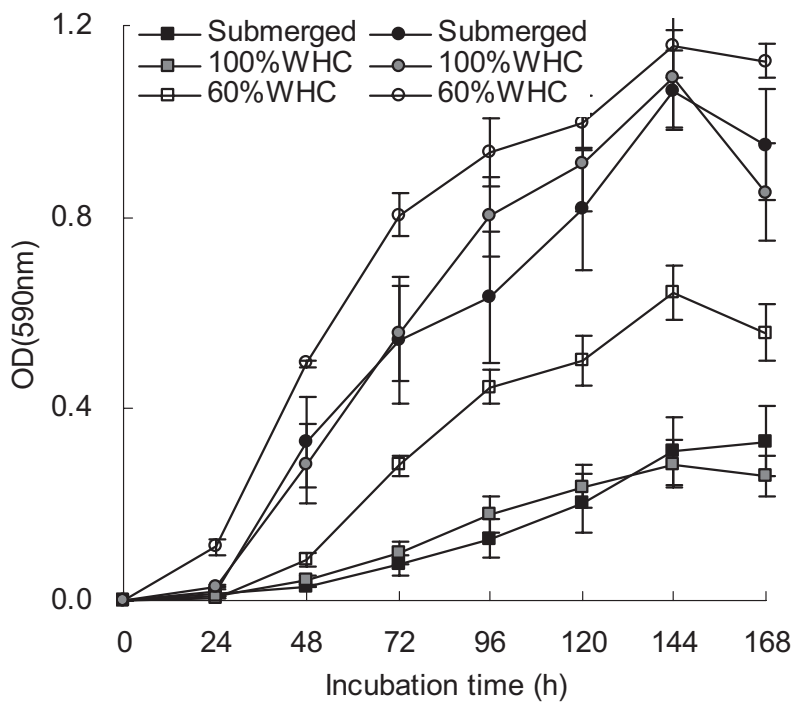

Figure 1: Average well-color development profiles (A590) (AWCD) for samples from rhizosphere soil (circles) and bulk soil (squares) in the water treatments submerged, $100 \% \mathrm{WHC}$, and $60 \% \mathrm{WHC}$.

bolic fingerprints indicated differences in substrate utilization between rhizosphere and non-rhizosphere. The second axis showed a clear separation of the submergence from $100 \%$ WHC and $60 \%$ WHC.

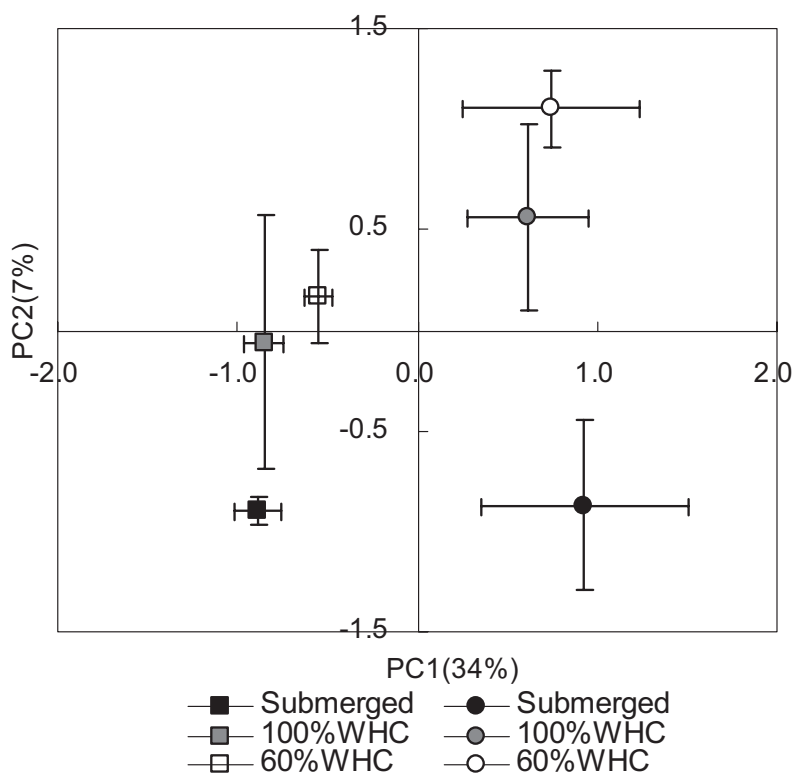

Figure 2: Principal-component analysis (PCA) performed on the Biolog data after $96 \mathrm{~h}$ incubation of soil extracts. Symbols: circles, rhizosphere soil; squares, bulk soil.
Microbial substrate-utilization potentials for six types of Biolog substrates (amino acid, carbohydrate, carboxylic acid, polymer, amine, miscellaneous) were determined using AWCD after $96 \mathrm{~h}$ of incubation (Fig. 3). Utilization of Biolog substrates was generally greater in the rhizosphere than in the non-rhizosphere, especially the utilization of carbohydrates. Utilization of amino acids, carbohydrates, and carboxylic acids was higher than that of the remaining substrates. Compared to other substrates, amine utilization was the lowest, irrespective of soil moisture content.

A t-test was performed to test the significant differences in Shannon richness and evenness between the water treatments (Tab. 2). Soil water treatments had a significant effect on Biolog Shannon richness and evenness; both parameters increased with decreasing soil moisture contents. The Shannon richness and evenness of the rhizosphere soil were much higher than those of the non-rhizosphere soil irrespective of soil water treatment.

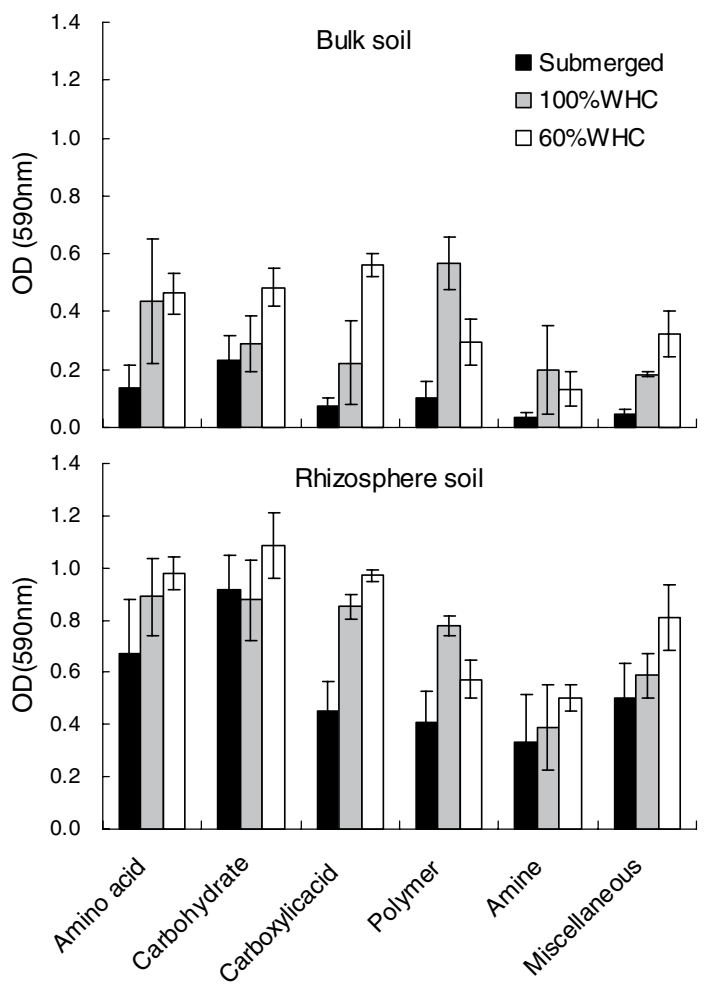

Figure 3: Six types of Biolog substrate-utilization potentials of microbial communities following different water regimes. Within each substrate, means $(n=4)$ followed by the same letter are not significantly different $(p<0.05)$.

Table 2: Shannon richness and evenness of AWCD after $96 \mathrm{~h}$ incubation of soil extracts from $60 \%$ WHC (water-holding capacity), $100 \%$ WHC, and submerged paddy soil. Means (mean $\pm \mathrm{SE}, \mathrm{n}=4$ ) followed by the same letter are not significantly different $(p<0.05)$.

\begin{tabular}{lllll}
\hline Water regime & Bulk soil & & Rhizosphere soil & \\
\cline { 2 - 5 } & Shannon richness & Shannon evenness & Shannon richness & Shannon evenness \\
\hline Submerged & $2.94 \pm 0.20 \mathrm{~b}$ & $0.69 \pm 0.04 \mathrm{~b}$ & $3.88 \pm 0.05 \mathrm{~b}$ & $0.89 \pm 0.01 \mathrm{c}$ \\
$100 \%$ WHC & $3.32 \pm 0.23 \mathrm{ab}$ & $0.83 \pm 0.03 \mathrm{a}$ & $4.13 \pm 0.04 \mathrm{a}$ & $0.92 \pm 0.01 \mathrm{~b}$ \\
$60 \%$ WHC & $3.73 \pm 0.06 \mathrm{a}$ & $0.86 \pm 0.02 \mathrm{a}$ & $4.24 \pm 0.04 \mathrm{a}$ & $0.94 \pm 0.01 \mathrm{a}$ \\
\hline
\end{tabular}




\subsection{Abundance of FeOB and FeRB}

Besides the submergence treatment, the densities both of FeOB and FeRB in the rhizosphere were one to two orders of magnitude higher than those in the non-rhizosphere (Tab. 3). The highest FeOB abundance was observed in the rhizosphere in the treatment of $100 \% \mathrm{WHC}$. The lowest FeOB abundance was $6.6 \times 10^{4}$ cells $\mathrm{g}^{-1}$ in the non-rhizosphere submerged soil, which also had the lowest FeRB density of $3.4 \times 10^{4}$ cells $\mathrm{g}^{-1}$. The FeOB and FeRB in the submerged paddy soil were lesser than in the other two treatments.

\section{Discussion}

\subsection{Effect of soil moisture on the formation of Fe plaque and adsorbed $P$}

The submerged rice roots formed more Fe plaque than roots in aerobic soil as reported before (Liang et al., 2006), as possibly larger amounts of dissolved $\mathrm{Fe}$ moved to rhizosphere and as the $\mathrm{Fe}(\mathrm{II})$ concentration increased both in the rhizosphere and bulk-soil solution after flooding. A subsequent decrease of the $\mathrm{Fe}(\mathrm{II})$ concentration in the soil solution could be the result of $\mathrm{Fe}$ (II) precipitation as siderite, vivianite, or $\mathrm{Fe}$ sulfide. Compared with the submerged soil, the treatments with $100 \%$ and $60 \%$ WHC underwent several drying-wetting cycles, resulting in changes of physical and chemical soil properties (e.g., redox potential, mobility of ferrous Fe). The mobility of ferrous Fe may have decreased because of its precipitation and adsorption to the soil matrix (Kirk, 2004). Similarly, Zhao et al. (2003) reported that DTPA-extractable $\mathrm{Fe}$ and exchangeable $\mathrm{Fe}$ in the soil significantly increased during flooding. A low Fe-plaque formation in the treatments with $100 \%$ and $60 \%$ WHC may indicate a low availability of mobile ferrous $\mathrm{Fe}$ in the soil. This study also conformed that the amount of Fe plaque decreased with the growth stage of the rice plants. The roots sampled at 11 weeks were significantly larger than those sampled at 5 weeks, visual appearance of reddish coating was not equal throughout the root system, and the root growth might outpace Fe-plaque formation. As a result, the Fe concentration, calculated on the basis of dry root weight, decreased with advancing growth stages. Increasing $\mathrm{Fe}(\mathrm{II})$ in the growth medium could effectively increase the formation of Fe plaque on rice roots (Liang et al., 2006; Liu et al., 2004b). It may be concluded that the formation of Fe plaque is closely associated with the concentration and the mobility of $\mathrm{Fe}$ in the soil.

Besides the dissolved $\mathrm{Fe}(\mathrm{II})$ in soil solution, the formation of Fe plaque on the rice root can be affected by factors such as oxygen released from rice roots, $\mathrm{P}$ starvation, and the rice genotypes (Armstrong, 1967; Liu et al., 2004a, b). The Feplaque formation on the root surface of wetland plants has been attributed to the gas exchange between the atmosphere and the anaerobic soils (Van der Nat and Middelburg, 1998). As a result, the change in oxygen transported from the conduit could influence the formation of Fe plaque. However, the morphology of rice roots under different water regimes was not observed in this study.

Similar to this study, Zhang et al. (1999) found that Fe plaque might act as a $\mathrm{P}$ pool. In the present study, the amount of $\mathrm{P}$ adsorbed on the Fe plaque was correlated with rice-plant biomass. This suggests that $P$ trapped in Fe plaque may be available to the plant, which is supported by Wigand and Sevenson (1997).

\subsection{Effect of soil moisture on the microorganisms}

The bacterial communities of rhizosphere and non-rhizosphere soil in the different treatments were also evaluated using Biolog. All data (AWCD, PCA, and six types of Biolog substrate utilization) indicated that the rhizosphere community differed from that in the non-rhizosphere. This agrees with numerous earlier reports (Kent and Triplett, 2002). A different utilization of $\mathrm{C}$ sources between rhizosphere and nonrhizosphere microorganisms suggests a different availability of these $\mathrm{C}$ sources in the rice rhizosphere and non-rhizosphere, which may influence the proliferation of particular communities of microorganisms. This microbial diversity may have arisen from the variation in $\mathrm{C}$ compounds exuded by the rice roots. In the present experiment, the microbial community utilized carbohydrates the most, but utilized amines and polymers poorly (Fig.3), suggesting that the microbes are adapted to simple rather than to complex $\mathrm{C}$ resources in rice rhizosphere.

Table 3: Most-probable-number (MPN) enumerations of Fe(II)-oxidizing bacteria (FeOB) and Fe(III)-reducing bacteria (FeRB) in rhizosphere and bulk paddy soil with different water regimes. Overflow of the MPN calculator version 4.05 with the series of dilution is denoted by a "NA".

\begin{tabular}{|c|c|c|c|c|}
\hline \multirow[t]{2}{*}{ Water regime } & \multicolumn{2}{|l|}{ FeOB } & \multicolumn{2}{|l|}{ FeRB } \\
\hline & MPN (cell g-1) & $95 \%$ confidence interval & MPN (cell g-1) & $95 \%$ confidence interval \\
\hline \multicolumn{5}{|l|}{ Bulk soil } \\
\hline Submerged & $6.6 \times 10^{4}$ & $1.6 \times 10^{4}-2.7 \times 10^{5}$ & $3.4 \times 10^{4}$ & $9.8 \times 10^{3}-1.2 \times 10^{5}$ \\
\hline $100 \% \mathrm{WHC}$ & $7.1 \times 10^{4}$ & $1.7 \times 10^{4}-3.0 \times 10^{5}$ & $6.0 \times 10^{5}$ & $1.5 \times 10^{5}-2.5 \times 10^{6}$ \\
\hline $60 \% \mathrm{WHC}$ & $7.7 \times 10^{4}$ & $1.8 \times 10^{4}-3.3 \times 10^{5}$ & $8.2 \times 10^{4}$ & $1.9 \times 10^{4}-3.6 \times 10^{5}$ \\
\hline \multicolumn{5}{|l|}{ Rhizosphere soil } \\
\hline Submerged & $5.4 \times 10^{4}$ & $1.3 \times 10^{4}-2.2 \times 10^{5}$ & $5.4 \times 10^{4}$ & $1.3 \times 10^{4}-2.2 \times 10^{5}$ \\
\hline $100 \% \mathrm{WHC}$ & NA & NA & $3.5 \times 10^{6}$ & $9.4 \times 10^{5}-1.3 \times 10^{7}$ \\
\hline $60 \%$ WHC & $9.0 \times 10^{5}$ & $2.1 \times 10^{5}-3.9 \times 10^{6}$ & $2.9 \times 10^{6}$ & $8.1 \times 10^{5}-1.0 \times 10^{7}$ \\
\hline
\end{tabular}


The changes in microbial-community diversity in response to different moisture contents were detected in the paddy soil. Similarly, effects of moisture content have been shown to influence the diversity and cultivable activity of bacterial communities in the rhizosphere of an established upland grassland soil (Griffiths et al., 2003). It was concluded that controlled soil drying decreased the substrate-utilization response, and subsequent re-wetting of dried soil led to the recovery of the microbial population. In the present study, abundances of FeOB and FeRB in the submerged soil were less than in the other two treatments. It is well known that in non-rhizosphere soil, anoxic conditions are established under flooded conditions and fermentation and methanogeneses are the major microbial pathways after depletion of other electron acceptors. Decreasing the water content changes the redox conditions towards oxic condition, and therefore the community will adapt to more aerobic microorganisms. It is known that under oxic condition, the species richness and evenness increases, and the oxic incubation condition may favor the aerobic bacteria. However, Biolog plate used for environmental probes has different drawbacks (Preston-Mafham et al., 2002). Although Biolog analysis has the limitation of selecting for fast growing bacteria, thereby promoting minimal fungal metabolism, and some fungi cannot reduce the tetrazolium dye (Dobranic and Zak, 1999), the growth-based techniques (Biolog) could partly indicate the relative diversity between different treatments, and it can be concluded that the submerged paddy soil contained fewer aerobic bacteria despite the microaerophilic environment of the rhizosphere. Soil moisture directly affects the osmotic status of bacterial cells and can indirectly regulate substrate availability, diffusion of gases, soil $\mathrm{pH}$, and temperature (Griffiths et al., 2003). As a consequence, these factors will induce changes of structure and function of soil bacterial communities.

\subsection{A rhizosphere Fe cycle}

In the present study, large numbers of FeOB and FeRB were found in both rhizosphere and non-rhizosphere. In general, FeOB and FeRB were more abundant in the rhizosphere than in non-rhizosphere indicating that a more rapid active $\mathrm{Fe}$ cycle may exist in the rhizosphere. It has been described that anaerobic $\mathrm{Fe}(\mathrm{II})$ oxidation is mediated by members of both Archaea and bacteria domains (Straub et al., 1996; Hafenbradl, 1996) in anoxic environments at circumneutral $\mathrm{pH}$. Furthermore, the high abundance of poorly crystalline Fe(III) minerals, which were the main component of Fe plaque, and high levels of labile carbon contributed to the high densities of acetate-utilizing FeRB in the rhizosphere. Weiss et al. (2004) found that the percentage of poorly crystalline Fe (III) was significantly correlated with the percentage of FeRB $(r=0.76)$, reflecting the fact that poorly crystalline $\mathrm{Fe}(\mathrm{III})$ minerals are labile with respect to microbial reduction. The FeRB consumed a large amount of poorly crystalline Fe(III) oxides of the Fe plaque with the incubation time. $Q u$ et al. (2004) found that Geobacter metallireducens GS-15 could only reduce poorly crystalline $\mathrm{Fe}$ (III) minerals in a 4-day incubation. The presence of $\mathrm{Fe}(\mathrm{III})$-dominated Fe plaque readily functions as electron acceptors for FeRB. On the other hand, the rhizosphere $\mathrm{Fe}(\mathrm{II})$ oxidation in paddy soils may be due to other biotic processes. For example, nitrate-reduction coupled to $\mathrm{Fe}(\mathrm{II})$ oxidation was reported in the rice paddy soil (Ratering and Schnell, 2001). The ubiquity and diversity of these anaerobic FeOB suggests that nitrate-dependent Fe(II) oxidation, light-independent reactions, have the potential to contribute to anoxic Fe oxidation in the rhizosphere, provided adequate concentrations of a suitable electron acceptor.

It is likely that the microbial metabolism affects the physical and chemical characteristics of the rhizosphere, and subsequently influences Fe-plaque formation. For example, microbial oxidation of root exudates (e.g., glucose, glycine, citrate, and malate) to $\mathrm{CO}_{2}$ might affect solution $\mathrm{pH}$ (Küsel et al., 2003). Similarly, it was reported that the $\mathrm{pH}$ of $\mathrm{Fe}$ solutions after exposure to axenic and non-axenic seedlings was significantly different (Johnson-Green and Crowder, 1991). The ability of Fe-oxidizing bacteria to compete with the chemical oxidation of $\mathrm{Fe}(\mathrm{II})$ may depend on the rhizosphere $\mathrm{pH}$. The kinetics of $\mathrm{Fe}$ oxidation are relatively slow at low $\mathrm{pH}(<4)$. At low $\mathrm{pH}$, Fe-oxidizing bacteria, such as Thiobacillus ferrooxidans, may increase Fe oxidation kinetics (Emerson et al., 1999) and thereby contribute to Fe-plaque formation. Therefore, there may be interactions between plaque formation and microbial processes. However, it is still unknown which species of bacteria play the key role in this process. Further studies are therefore needed to investigate some functional bacteria (e.g., Fe-oxidizing or Fe-reducing bacteria), which may be important in Fe-plaque formation.

\section{Conclusion}

To conclude, our data implicate marked differences in Fe-plaque formation and soil microbial-community composition in the different soil water treatments. High soil moisture content increased the formation of Fe plaque and in consequence the $P$ adsorption on the root surface. Moreover, based on substrate-utilization analyses, significant changes were observed for the total microbial community in the different moisture treatments. With low moisture content, CCLP of the paddy soil increased, and that of the rhizosphere was significantly higher than that of the bulk soil. Further studies are warranted on some functional bacteria (e.g., Fe-oxidizing or Fe-reducing bacteria), which may be important in Fe-plaque formation and in providing insights into the mechanism of Fe-plaque formation.

\section{Acknowledgments}

The study is financially supported by the Natural Science Foundation of China (40621061 and 40671102).

\section{References}

Ando, T., Yoshida, S., Nishiyama, I. (1983): Nature of oxidizing power of rice roots. Plant Soil 72, 57-71.

Armstrong, W. (1967): The oxidising activity of roots in water-logged soils. Physiol. Plant. 20, 920-926.

Chen, C. C., Dickson, J. B., Turner, F. T. (1980): Iron coating on rice roots: morphology and models of development. Soil Sci. Soc. Am. J. 44, 1113-1119. 
Christensen, K. K., Wigand, C. (1998): Formation of root plaques and their influence on tissue phosphorus content in Lobelia cortmanna. Aquat. Bot. 61, 111-122.

Chistensen, K. K., Andersen, F. O., Jensen, H. S. (1997): Comparison of iron, manganese and phosphorus retention in fresh water littoral sediment with growth of Littorella uniflora and benthic microalgae. Biogeochem. 38, 149-171.

Dobranic, J. K., Zak, J. C. (1999): A microtiter plate procedure for evaluating fungal functional diversity. Mycologia 91, 756-765.

Emerson, D., Weiss, J. V., Megonigal, J. P. (1999): Iron-oxidizing bacteria are associated with ferric hydroxie precipitates (Feplaque) on the roots of wetland plants. Appl. Environ. Microbiol. 65, 2758-2761.

Garland, J. L., Mills, A. L. (1991): Classification and characterization of heterotrophic microbial communities on the basis of patterns of community-level sole-carbon-source utilization. Appl. Environ. Microbiol. 57, 2351-2359.

Griffiths, R. I., Whiteley, A. S., O'Donnell, A. G., Bailey, M. J. (2003): Physiological and community responses of established grassland bacterial populations to water stress. Appl. Environ. Microbiol. 69, 6961-6968.

Hafenbradl, D. (1996): Ferroglobus placidus gen. nov. sp. nov. a novel hyperthermophilic archaeum that oxidizes $\mathrm{Fe}$ (II) at neutral $\mathrm{pH}$ under anoxic conditions. Arch. Microbiol. 166, 308-314.

Hansel, C. M., Fendorf, S., Sutton, S., Newville, M. (2001): Characterization of Fe plaque and associated metals on the roots of minewaste impacted aquatic plants. Environ. Sci. Technol. 35, 3863-3868.

Johnson-Green, P. C., Crowder, A. A. (1991): Iron oxide deposition on axenic and non-axenic roots of rice seedlings (Oryza sativa L.). J. Plant Nutr. 14, 375-385.

Kent, A. D., Triplett, E. W. (2002): Microbial communities and their interactions in soil and rhizosphere ecosystems. Ann. Rev. Microbiol. 56, 211-236.

King, G. M., Garey, M. A. (1999): Ferric iron reduction by bacteria associated with the roots of rice seedlings (Orzya sativa). J. Plant Nutr. 14, 375-386.

Kirk, G. (2004): The biogeochemistry of submerged soils. John Wiley and Sons, Chichester, UK.

Küsel, K., Chabbi, A., Trinkwalter, T. (2003): Microbial processes associated with roots of bulbous rush coated with iron plaques. Microbial Ecol. 46, 302-311.

Liang, Y., Zhu, Y. G., Xia, Y., Li, Z., Ma, Y. (2006): Iron plaque enhances phosphorus uptake by rice (Oryza sativa) growing under varying phosphorus and iron concentrations. Ann. Appl. Biol. 149, 305-312.

Liu, W. J., Zhu, Y. G., Smith, F. A., Smith, S. E. (2004a): Do phosphorus nutrition and iron plaque alter arsenate (As) uptake by rice seedlings in hydroponic culture? New Phytol. 162, 481-488.

Liu, W. J., Zhu, Y. G., Smith, F. A., Smith, S. E. (2004b): Do iron plaque and genotypes affect arsenate uptake and translocation by rice seedlings (Oryza sativa L.) grown in solution culture? J. Exp. Bot. 55, 1707-1713.

Lu, R. K. (1999): Analytical Methods for Soil and Agricultural Chemistry. China Agricultural Science and Technology, Publishing House, Beijing (in Chinese).
Macfie, S. M., Crowder, A. A. (1987): Soil factors influencing ferric hydroxide plaque-formation on roots of Typha latifolia. Plant Soil 102, 177-184.

Nicolaisen, M. H., Risgaard-Petersen, N., Revsbech, N. P., Reichardt, W., Ramsing, N. B. (2004): Nitrification-denitrification dynamics and community structure of ammonia oxidizing bacteria in a high yield irrigated Philippine rice field. FEMS Microbiol. Ecol. 49, 359-369.

Preston-Mafham, J., Boddy, L., Randerson, P. F. (2002): Analysis of microbial community functional diversity using soli-carbon-source utilization profiles: a critique. FEMS Microbiol. Ecol. 42, 1-4.

Qu, D., Ratering, S., Schnell, S. (2004): Microbial reduction of weakly crystalline Iron oxides and suppression on methanogenesis in paddy soil. Bull Environ. Contamin. Toxicol. 72, 1172-1181.

Ratering, S., Schnell, S. (2001): Nitrate-dependent iron (II) oxidation in paddy soil. Environ. Microbiol. 3, 100-109.

Schutter, M. E., Dick, R. P. (2001): Shifts in substrate utilization potential and structure of soil microbial communities in response to carbon substrates. Soil Biol. Biochem. 33, 1947-1958.

Schwertmann, U., Cornell, R. M. (2000): Iron oxides in the laboratory: preparation and characterization. Wiley- $\mathrm{VCH}$, Weinheim, Germany.

Stookey, L. L. (1970): Ferrozine - a new spectrophotometric reagent for iron. Anal. Chem. 42, 779-781.

Straub, K. L., Benz, M., Schink, B., Widdel, F. (1996): Anearobic, nitrate-dependent microbial oxidation of ferrous iron. Appl. Environ. Microbiol. 62, 1458-1460.

Taylor, G. J., Crowder, A. A. (1983): Use of DCB technique for extraction of hydrous iron on roots of common reeds. Soil Sci. Soc. Am. J. 60, 323-329.

Van der Nat, F. J. W. A., Middelburg, J. J. (1998): Effects of two common macrophytes on methane dynamics in freshwater sediments. Biogeochem. 43, 79-104.

Weiss, J. V., Emerson, D., Backer, S. M., Megonigal, J. P. (2003): Enumeration of $\mathrm{Fe}(\mathrm{II})$-oxidizing and $\mathrm{Fe}$ (III)-reducing bacteria in the root zone of wetland plants: Implications for a rhizosphere iron cycle. Biogeochem. 64, 77-96.

Weiss, J. V., Emerson, D., Megonigal, P. (2004): Geochemical control of microbial $\mathrm{Fe}$ (III)-reduction potential in wetlands: comparison of the rhizosphere to non-rhizosphere soil. FEMS Microbiol. Ecol. 48, 89-100.

Widdel, F., Bak, F. (1992): Gram-negative mesophilic sulphate-reducing bacteria, in: Prokaryotes, Vol. 4. 2nd edn., Springer-Verlag, New York.

Wigand, C., Sevenson, J. C. (1997): Facilitation of phosphate assimilation by aquatic mycorrhizae of Vallisneria americana Michx. Hydrobiologia 342, 35-41.

Zak, J. C., Willig, M. R., Moothead, D. L., Wildman, H. G. (1994): Functional diversity of microbial communities: a quantitative approach. Soil Biol. Biochem. 26, 1101-1108.

Zhang, X. K., Zhang, F. S., Mao, D. R. (1999): Effect of iron plaque outside roots on nutrient uptake by rice (Oryza sativa L): Phosphorous uptake. Plant Soil 209, 187-192.

Zhao, C. F., Liu, X. J., Lü, S. H., Zhang, F. S. (2003): (in Chinese) Effects of water and fertilization conditions on Fe movement and its uptake by rice. J. China Agr. Univer. 8, 74-78. 